\title{
LA DESCRIPCIÓN DEL SAYYID ÁRABE EN UNA FUENTE LEVANTINA DEL SIGLO XI Y EL SOBRENOMBRE DEL CID
}

\author{
José Ramírez del Río**
}

\section{INTRODUCCIÓN}

El sobrenombre dado a Rodrigo Díaz de Vivar, el Cid, ha sido objeto de atención de los especialistas en distintos momentos de la historia ${ }^{1}$. La idea más aceptada ha sido la correspondencia de este Cid con la palabra árabe sayyid que, en una pronunciación propia del dialecto andalusí ${ }^{2}$, elimina la diptongación para pasar a un sonido / $\overline{1}$ / largo, y transforma la sin en un sonido cercano a la zeta castellana. La antigüedad de este apelativo queda atestiguada por distintos testimonios literarios, como el Cantar de Almería, que se refiere a Rodrigo Díaz como "mio Cid saepe vocatur" ${ }^{3}$, por lo que sabemos que esta denominación no fue una invención o un embellecimiento literario posterior sino un apelativo recibido por este personaje en vida, posiblemente utilizado por los andalusíes que combatieron a su servicio, como veremos más adelante. En su

* Un primer borrador de este trabajo fue presentado a las jornadas El Cid en las fuentes árabes y latinas medievales, celebradas en Burgos, en noviembre de 2006. El texto final ha sido considerablemente ampliado y ha tenido en cuenta diferentes aportaciones de los últimos años.

Este artículo se ha llevado a cabo dentro del proyecto de investigación "Crueldad y compasión en la literatura árabo-islámica: una contribución a la historia de las emociones" (ref. HUM2006-04475/FILO).

** Universidad de Córdoba.

1. R. Menéndez Pidal, La España del Cid, Madrid, 19697, p. 555 y Cantar de Mio Cid. Texto, gramática y vocabulario, Madrid, 1969, II, pp. 574-577; A. GALMÉs DE FUENTES, «Épica árabe y épica castellana. Problema crítico en sus posibles relaciones», La poesia epica e la sua formazione, Roma, 1970, pp. 212-214 y del mismo autor: La épica románica y la tradición árabe, Madrid, Gredos, 2002, p. 143. Galmés defiende en este último trabajo la procedencia del apelativo del Cid Campeador del del emir Abū Muhammad: Sayyid al-Baț̣āl.

2. F. CORRIENTE, Árabe andalusí y lenguas romances, Madrid, 1992, pp. 41-42. Sin estar generalizada en absoluta la monoptongación, sí se producía en contextos muy diversos.

3. F. CAstro, El cantar de la conquista de Almería por Alfonso VII, Almería, 1992. 
traducción del Poema de Mio Cid al árabe el hispanista egipcio Țāhir 'Alī Makki utilizó la palabra árabe سيد sayyid para el nombre del héroe ${ }^{4}$, pues además de considerar que la palabra castellana procedía de este vocablo, la descripción que se ofrecía de Rodrigo Díaz en el poema no sólo no resultaba chocante sino que se correspondía bastante con la descripción de los personajes que recibían este apelativo en la tradición árabe; otros autores árabes han seguido la misma línea en su acercamiento a esta figura, como Simón Hayek, que en su obra acerca del Cid lo equipara con otro gran héroe y sayyid de la literatura árabe, 'Antara b. Šaddād ${ }^{5}$. Resulta llamativo el hecho de que tanto Makkī como otros estudiosos árabes han considerado tan evidente el origen de la palabra Cid en sayyid que ni tan siquiera hayan dedicado espacio a justificar su decisión. Las fuentes árabes contemporáneas o poco posteriores no le daban este apelativo, como ha indicado la Dra. Viguera ${ }^{6}$ en su exposición acerca de las fuentes árabes. Esta autora señaló la referencia de la Primera Crónica General ${ }^{7}$ en el sentido de que este epíteto le fue aplicado, junto con el romance de Campeador [alQanbiyyatūr], tras la campaña que efectuó a favor del rey de la taifa de Sevilla, al-Mu'tamid, en Cabra. Es la explicación más antigua con la que contamos acerca del apelativo del héroe castellano.

El sobrenombre sayyid fue utilizado en distintos momentos en al-Andalus: contamos con algunos testimonios de los cronistas árabes acerca de su uso con los primeros omeyas ${ }^{8}$, Ibn $\mathrm{Abī}$ 'Āmir, Almanzor, adoptó este apelativo en el año $996^{9}$, y un buen número de reyes de taifas adoptaron títulos en los que entraba esta palabra: al-sayyid al-muzaffar, sayyid al-dawla, etc. ${ }^{10}$. En los siglos XII y XIII encontramos esta palabra utilizada en la cancillería almohade como título de respeto hacia los descendientes del califa 'Abd al-Mu' $\mathrm{min}^{11}$, que solían ocupar los principales gobiernos de las ciudades de al-Andalus y el Magreb durante este período, aunque por otras referencias sabemos que incluso entonces fue aplicado a otras personas respondiendo a su sentido anterior de jefe de

4. Malhamat al-sayyid, trad. al árabe, introducción y notas Țāhir 'Alī Makkī, El Cairo, 1995, 4ª edición. Lógicamente cuando el apelativo se refiere al propio Cid el traductor pone especial cuidado en vocalizar la palabra con kesra: سِيّد

5. S. HAYEK, "Al-sayyid", 'Antara al-asbān, Beirut, 1974. Otros ejemplos de autores árabes que adoptaron esta palabra como forma de traducir el apelativo de Rodrigo Díaz son: Muhammad GANİMī, Al-adab al-muqāran, El Cairo, $1963^{2}$, pp. 300-301 o Muhammad AL-MufīD, Rihlat aladab al-'arabī ilà urubba, El Cairo, 1968, pp. 241-244.

6. M. ${ }^{a}$ J. Viguera Molins, «El Cid en las fuentes árabes», Actas del Congreso Internacional. Burgos 1999, Burgos, 2000, pp. 55-92, especialmente pp. 85-86.

7. Ed. R. Menéndez Pidal, Madrid, 1955, capítulo 849, pp. 522-523.

8. Al-MAQQARİ, Al-Nafh al-țib, ed. III. 'Abbas, Beirut, 1968, I, p. 216.

9. J. VAllvé, El califato de Córdoba, Madrid, Mapfre, 1992, p. 236.

10. M. J. Jiguera Molins, op. cit., pp. 85-86.

11. Cfr. Ibn Șāhịib AL-ȘALÀ, Al-Mann bi-l-imāma, Beirut, 1987; Ibn 'ID̄ĀRĪ, Al-Bayān al-mugrib, ed. M. Kattān̄ et alii, Rabat, 1985; E. MolinA, Ceyt Abu Cayt. Novedades y rectificaciones, Murcia, 1977. 
tribu. En su reciente obra acerca de la génesis del Cantar, D. Oliver ha señalado este apelativo como otra evidencia de la autoría árabe del poema ${ }^{12}$.

A pesar de la amplia aceptación de esta teoría no ha dejado de haber otras propuestas como la muy bien documentada propuesta de M. de Epalza ${ }^{13}$ que relacionaba la palabra Cid con șīd, una palabra que también habría sufrido un cierto grado de alteración en el dialecto andalusí pero que procedería de león y habría correspondido a un título o un sobrenombre honorífico propio de los militares almohades, imperio cuyo dominio sobre al-Andalus se corresponde con las fechas propuestas para la elaboración final del Cantar.

Resulta difícil discernir las posibilidades de estas teorías, pues cada una de ellas permite resolver un cierto número de problemas; así la propuesta de $\mathrm{M}$. de Epalza permite profundizar en algunos episodios del Cantar como el del león, que resulta extraordinariamente semejante a una leyenda acerca del califa almohade 'Abd al-Mu' $\min ^{14}$; sin embargo nos debemos inclinar por el origen del apelativo Cid en el vocablo árabe sayyid. El episodio del león en el CMC requiere, a nuestro parecer, una reevaluación en profundidad, pues varias de las claves del texto se encuentran en él. Cuando A. Montaner, en la introducción de su excelente edición ${ }^{15}$, señala que el texto presenta una notable unidad, este episodio ${ }^{16}$ y el del arcángel Gabriel ${ }^{17}$ parecen ser dejados de lado. Si el CMC es un texto, en general, notablemente verista, en que las circunstancias más duras e incluso humillantes de la vida del héroe son expuestas de forma descarnada, en los casos citados se desvían de este estilo de manera clara. Así, en los versos 404 a 411 el arcángel Gabriel comunica en sueños al Cid que su destierro sólo es el comienzo de una época venturosa para él. El comienzo del canto tercero, entre los versos 2278 y 2310, en el episodio del león, nos muestra también un estilo muy diferente. El animal sale de su red y comienza a vagar por el palacio de Valencia, cerca de donde el Cid duerme. Mientras los infantes de Carrión huyen, escondiéndose y manchando sus ropas, los soldados del Cid, desarmados, se interponen entre éste y el león. Cuando Rodrigo Díaz despierta, va hacia el león que se somete a él, y lo conduce de vuelta a su red ante el asom-

12. D. Oliver, El Cantar de Mío Cid. Génesis y autoría árabe, Almería, 2008, pp. 15-22. Tenemos que señalar respecto a esta obra, que explica de forma notable algunos aspectos del $C M C$, en especial la parte bélica, que su hipótesis principal, la autoría de al-Waqqasi con la colaboración de Sandal, no resulta sólida y no puede ser tomada en consideración en estos momentos, a pesar del interés de algunos de los argumentos presentados.

13. M. DE EpAlzA, «El Cid = El León: ¿Epíteto árabe del Campeador?», Hispanic Review, 45, 1, 1977, pp. 67-75 y del mismo autor: «El Cid como antropónimo (“el León”) y como topónimo ("el señor o gobernador almohade")», Sharq al-Andalus, 7, 1990, pp. 157-169.

14. Cfr. A. Huici Miranda, Historia política del imperio almohade, ed. facsimilar con introducción de E. Molina y E. Navarro, Granada, 2000.

15. Cantar de Mio Cid, edición, introducción y notas de A. Montaner, Barcelona, 2007, pp. LXXXLXXXIV.

16. Idem, versos 2278-2310.

17. Idem, versos 404-411. 
bro de los presentes. El hecho de que este episodio sea un añadido posterior, obra del segundo juglar del cantar, se ve reforzado a nuestro entender por el hecho de que la identificación entre el león y la dignidad regia se había acentuado mucho en época de Alfonso VIII, a comienzos del s. XII, como podemos observar en los siguientes pasajes del Tudense ${ }^{18}$ :

"Iste rex Adefonsus primo castellum in armis suis depinxit, quamuis antiqui reges patres ipsius leonem depingere consuerant, eo quod leo interpretatur rex uel est rex ómnium bestiarum...".

Y sólo un poco más adelante:

"et tam terribilis fuit cunctis male agentibus, quod eius aspectum non possent aliquatemus sustinere. Vox eius in ira quasi leo rugiens uidebatur...".

Por tanto la identificación de este descendiente del Cid con el león, y la adopción del mismo como símbolo de la autoridad regia no sólo se había acentuado en tiempos de Alfonso VIII, sino que se había convertido en una de las formas de caracterizar al propio rey.

La diversidad de teorías acerca de la palabra sayyid y el hecho de que se haya aplicado este apelativo árabe en diferentes ocasiones, no deben conducirnos a suponer que esta palabra hiciera referencia a un tratamiento respetuoso un tanto vago o a una figura poco concreta. En estas páginas abordaremos las noticias que en el al-Andalus de la época había acerca de los sādāt [plural árabe de la palabra sayyid, aunque por comodidad expositiva utilizaremos en adelante el plural castellano], con especial incidencia en la obra del polígrafo Ibn 'Abd al-Barr Bahŷat al-maŷālis ${ }^{19}$, pero sin dejar de aludir a otras obras en las que se menciona la existencia de estos personajes en la Península Ibérica entre los siglos XI y XIII. Podremos comprobar que esta palabra hacía referencia a una realidad bien definida, y con perfiles muy acusados en la cultura árabe en general y en la andalusí en particular.

Es necesario incidir, aunque sea brevemente, en las personas que comenzaron a utilizar este apelativo para referirse a Rodrigo Díaz. Por lo general se asume que debieron ser los propios andalusíes que servían al Cid. Ibn al-Kardabūs nos transmitió noticias acerca de estos militares, que tras la caída de Valencia en manos de los almorávides hubieron de huir a Castilla:

“Y en ese tiempo se juntaron al Campeador y a otros como él un gran número

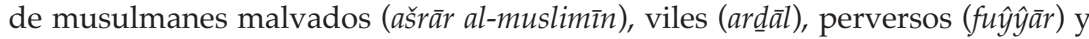
depravados (fāsid), y otros así que obraban como ellos, llamados 'los ambulantes'

18. Lucae Tudensis Chronicon Mundi, ed. y estudio E. Falque, Turnhout, 2003, p. 325.

19. Aunque la traducción de los títulos de las obras árabes medievales pueda resultar poco adecuada en algunos casos, consideramos necesario señalar al comienzo que Bahŷat al-maŷālis significa "Ornamento de las tertulias"; en adelante utilizaremos la transliteración del título. La edición que hemos podido utilizar de esta obra es la editada en Beirut por Muhammad Mūsà al-Jūlī y 'Abd al-Q̄āir al-Quțt, El Cairo, Dār al-mișriyya li-l-tā'lif wa-l-tarȳama, s.d. 
(al-daw $\left.\bar{a}^{\prime} i r\right)$, que contra los musulmanes lanzaban algaras, entraban a sus harenes, mataban a los hombres y robaban a las mujeres y a los niños. Muchos de ellos renegaban del Islam y abandonaban la Ley del Profeta, Dios le bendiga y le salve, hasta llegar a vender a un musulmán cautivo por un pan, una medida de vino y un arrelde de pescado, y a quien no podía rescatarse le cortaban la lengua, le vaciaban los ojos y le soltaban los perros de presa que lo destrozaban. Un grupo de ellos se había juntado con Alvar Fáñez, maldígalo Dios y a ellos también, y cortaban los sexos a hombres y mujeres, contando entre sus criados y agentes. Grave alteración habían sufrido en sus creencias, perdiendo por entero su fe" $\mathrm{fe}^{\prime 20}$.

Las descripciones de las fuentes árabes acerca de los tornadizos o apóstatas son, como no podía ser de otra manera, muy negativas. De ellas podríamos deducir que sólo se aliaron con Rodrigo Díaz una serie de individuos brutales y sin formación alguna, grupos de la población menos instruida y más baja de al-Andalus. Sin embargo la investigación que llevó a cabo E. Lévi-Provençal ${ }^{21}$ acerca de una fuente de La Primera Crónica General, Ibn 'Alqama, y la que llevamos a cabo acerca de la Leyenda de Cardeñ $a^{22}$, conducen a la evidencia de que personas con una educación bastante esmerada, generalmente vinculadas con el rey de las taifas de Toledo y de Valencia, al-Qādir, tuvieron una posición relevante en la corte valenciana del $\mathrm{Cid}$, al que trataban con mucha frecuencia ${ }^{23}$. La narración de Ibn Bassām acerca del entusiasmo del Campeador por las hazañas de al-Muhallab permitió a Maḥmūd 'Alī Makk $\overline{\mathbf{i}}^{24}$ determinar que la obra que le leían era un comentario que el juez de los musulmanes de Valencia, alWaqqašī, escribió acerca de una gran obra de la lexicografía árabe, el Kāmil de Mubarrad, cuya tercera parte estaba dedicada a las hazañas de este emir de Iraq. Por tanto debemos señalar que entre los andalusíes que apoyaron a Rodrigo Díaz en su aventura hubo un núcleo de personas de formación extraordinaria, que conocían a fondo tanto la lengua como la historia y la literatura árabes.

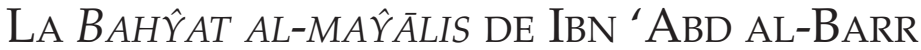

Hemos elegido la Bahŷat al-maŷālis tanto por el desarrollo que en esta obra encontramos de la caracterización del sayyid árabe como por la cercanía temporal y geográfica del autor de la misma a la aparición del Cid en el Levante.

20. Ibn Al-KardabŪs, Ta'rij al-Andalus, RIEI XIII, 1965-1966, p. 102, trad. M. ${ }^{a}$ J. Viguera Molins, op. cit., pp. 66-67.

21. «La toma de Valencia por el Cid según las fuentes musulmanas y el original árabe de la Crónica General de España», Al-Andalus, XIII, 1948, pp. 97-156.

22. Cfr. J. Ramírez del Río, La leyenda de Cardeña y la épica de al-Andalus, Sevilla, 2001.

23. A. Montaner también señala la presencia de musulmanes andalusíes contrarios a los almorávides precisamente por la amenaza que suponían a la propia cultura de al-Andalus. Cfr. Guerra en Šarq al-Andalus: Las batallas cidianas de Morella (1084) y Cuarte (1094), Zaragoza, 2005, p. 224.

24. M.A. MAKKI, «Los arabismos del Cantar de Mio Cid», El Cid, poema e historia, Actas del Congreso Internacional, ed. C. Hernández, Burgos, 1999, pp. 205-213. 
Ibn 'Abd al-Barr ${ }^{25}$ (368/978-463/1071) fue una de las figuras intelectuales más destacadas del siglo XI en al-Andalus y aún hoy sus obras son usadas como referencia en el mundo árabe. Tras formarse junto a algunos de los maestros más destacados de Córdoba, como Ibn al-Faraḍī, hubo de huir a la taifa de Denia debido a los disturbios de la guerra civil que significó el hundimiento del califato de Córdoba y en la que fueron asesinados algunos de sus maestros directos, trabajando durante algún tiempo para el rey al-Muŷahhid. Durante su período de formación mantuvo relaciones, por lo general amistosas, con personajes de la altura de Ibn Hazm e Ibn Zaydūn.

Su obra se centró principalmente en el hadi $\underline{t}^{26}$, y en las ciencias religiosas, pero sus conocimientos eran muy amplios y compuso obras de muy distinto tipo. Durante su relación con el rey de la taifa de Badajoz al-Muzaffar, que lo designó juez de Lisboa y de Santarén, compuso distintas obras relativas a la Arabia preislámica y a los primeros tiempos del islam. Tras la muerte del soberano afțāsí (1063) mantuvo una corta estancia en la corte de los 'abbādíes de Sevilla para interceder a favor de su hijo, que había alcanzado en este reino el cargo de kātib, de secretario de cancillería, para caer luego en desgracia; hubo de salir de esta ciudad y se dirigió de nuevo hacia el Šarq al-Andalus, donde se estableció finalmente y tras pasar por distintas ciudades de la región terminó encontrando acomodo en Játiva, donde murió en el año 1071.

Resulta difícil determinar la fecha en que compuso su obra Bahŷat almaỹālis ${ }^{27}$ pues no hay menciones expresas en el texto al momento de la redacción de la obra. Sin embargo hemos de tener en cuenta que dada la extensión de la obra y su carácter misceláneo debió requerir un período largo de composición pues sus ciento veinticuatro capítulos difícilmente serían escritos en una única ocasión, teniendo en cuenta las muchas obligaciones políticas, administrativas y científicas de Ibn 'Abd al-Barr. Hay muchas referencias que pudo tomar de otras obras compuestas para el rey de la taifa pacense, donde debió de escribir al menos una parte de la misma, pero posiblemente ésta no fuera concluida hasta que el retiro en Levante concediera a este literato andalusí la oportunidad para volcarse en la redacción de libros. Por tanto nos inclinamos a considerar que la obra es producto de diferentes momentos en la vida del autor, que le daría su conclusión durante su estancia en distintas ciudades del reino de Denia, entre el año 1064 y el 1071, fecha de su muerte. Si tenemos en cuenta que la primera aparición de Rodrigo Díaz por tierras valencianas posiblemente se produjera por primera vez durante la campaña emprendida por

25. J. HERnÁNDEZ JUBERÍAS, «Ibn 'Abd al-Barr en la Ŷadwa de al-Humaydi», Estudios onomásticobiográficos de al-Andalus, VI, ed. Manuela Marín, Madrid, 1994, pp. 217-248.

26. A.N.M. RAISUDDIN, Ibn Abd al-Barr and his Contribution to the Study of Hadith Literature in Spain, Dhaka, 1994.

27. Acerca de esta obra cfr. R. PINILLA, «Una obra andalusí de adab: la Bahŷat al-maȳālis de Ibn 'Abd al-Barr», Sharq al-Andalus, 6, 1989, pp. 83-101. 
el primer rey de Castilla, Fernando I, contra la capital del Turia en el año $1065^{28}$, podemos apreciar la importancia que tiene la descripción del sayyid árabe en esta obra para el análisis del uso que dicha palabra tenía en el Levante de la época, y su relación con el apelativo de Rodrigo Díaz.

La Bahŷat al-mâyālis pertenece al género de $a d a b^{29}$, que representa como ningún otro el interés de los árabes de los siglos IX y X por el conocimiento y las ciencias en todas sus variantes. Este género permitía al autor abordar cualquier tema, ya fuera histórico, relativo a la botánica, a la farmacopea, a la genealogía o a las matemáticas, para ofrecer al lector una serie de conocimientos estimados como necesarios para un hombre culto de su tiempo. El objetivo de estas obras era el de educar y enseñar al lector proporcionándole a la vez entretenimiento. Este género fue evolucionando en al-Andalus de forma notable, en buena medida gracias a la recepción de las obras maestras del género, compuestas en Oriente por al-Ŷăhiz ${ }^{30}$ e Ibn Qutayba ${ }^{31}$, y por el mayor dominio que iban adquiriendo los propios escritores andalusíes mediante la práctica. La primera obra notable que produjeron los escritores andalusíes la compuso Ibn 'Abd Rabbih a comienzos del siglo X, el 'Iqd [el collar] título al que un escribano añadió el adjetivo de al-farìd [único], a la que dedicamos anteriormente algunos trabajos. Sin embargo, la madurez del adab en la Península Ibérica la podemos asociar a la Bahŷat al-maŷālis.

Las fuentes de esta obra fueron muy amplias: las obras de Ibn Qutayba,

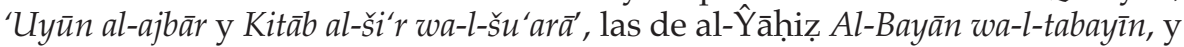
Al-Hayawān, distintas obras de lexicografía de al-Ajfaš, Ibn Durayd y Abū 'Alī al-Qālī, la ya mencionada obra de Ibn 'Abd Rabbihī el 'Iqd al-farīd, libros de recopilaciones de sentencias [amțāl] de al-Așma'î, al-Maydanī y Abū 'Ubayd alBakrī, las antologías de poesía tribal como la Hamāsa de Abū Tammām y al-Buhturī y otras obras más difíciles de encuadrar en un género como el Kitāb alKāmil de Mubarrad, que podemos destacar por su importancia pero que acompañan a otras muchas.

28. R. FletCHER, The Quest for the Cid [trad. al español J. Sánchez, El Cid, Barcelona, 1989, p. 118].

29. Cfr. F. RoldÁn CASTRO, El occidente de al-Andalus en el Atar al-bilad de al-Qazwini, Sevilla, 1990, p. 25 y ss.; R. ALLEN, The Arabic Literary Heritage: the Development of its Genres and Criticism, Cambridge, 1998; M. GÓMEz RENAU, «Influencia de la literatura de adab en el origen de la prosa literaria y la cuentística castellana», Anaquel de estudios árabes, 11, 2000, pp. 321-331.

30. Ch. Pellat, «Al-Djāhịiz», E.I. ${ }^{2}$, III, pp. 113-114. J. SKARZYNSKA-BoCHENSKA, «Al-Jahiz on poetry and poets», Occasional Papers of the School of Abbasid Studies, 4, 1992-1994, pp. 62-94; V. COLOMBO, «Considerazioni su Gahiz (1)», Istituto Lombardo: Randiconti, 126, ff. 1-2, 1993, pp. 19-24; AL-JaHIZ, Nine essays of al-Jahiz, trad. W.M. Hutchins, Nueva York, 1989; Ch. PeLlat, «Nouvel essai d'inventaire de l'oevre Gahizienne», Arabica, 31, 1984, pp. 117-164, del mismo autor: «À propos du Kitab al-Futya de Jahiz», Studies in honor of H.A.R. Gibb, 1965, pp. 538-546.

31. G. LECOMTE, «Ibn Kutayba», E.I. ${ }^{2}$, III, pp. 870-871; GAL, I, pp. 124-127; GALS, I, pp. 184-187; GAS, VIII, pp. 161-165; E. RIAD, «Deux détails de la préface du Kitab adab al-Katib d'Ibn Qutayba», Orientalia Suecana, 38-39, 1989-1990, pp. 140-148; G. LECOMTE, «Sur une relation de la Saqifa attibué a Ibn Qutayba», Studia Islamica, 31, 1970, pp. 171-183 y del mismo autor: «Ibn Qutayba (m. 276/889), l'homme. Son oevre, ses idées», Arabica, 13, 1966, pp. 173-196; S.A. BONEBAKKER, «Notes on some old manuscripts», Oriens, 13-14, 1960-1961, pp. 159-194. 
Ibn 'Abd al-Barr no las menciona pero también hemos de incluir en las fuentes que utilizó las obras de Mațālib al'arab (Defectos de los árabes) y Manāqib al-'arab (Virtudes de los árabes) pues a lo largo de su obra utiliza de forma habitual el procedimiento de mahāsin/masāwo que consiste en alabar y censurar al mismo tiempo un objeto, o en contrapesar virtudes y defectos, aspectos positivos y negativos...

\section{LAS CARACTERÍSTICAS DE LOS SĀDĀT \\ EN LA BAHŶAT AL-MAŶ̄ALIS. COMPARACIÓN CON EL CMC}

El análisis que vamos a llevar a cabo se centra fundamentalmente en el capítulo dedicado a las condiciones que ha de cumplir un guerrero para alcanzar la calidad de sayyid de su tribu, que es el capítulo sesenta y nueve, Bāb makārim al-ajlāq wa-l-su'dad" ["Capítulo sobre la nobleza de las costumbres y el ser sayyid"]; sin embargo tenemos que destacar desde un primer momento que las páginas dedicadas a este asunto se vieron complementadas por otras de la misma obra, pues el autor citó una serie de virtudes necesarias en un sayyid y posteriormente, en distintos apartados, desarrolló alguno de los aspectos expuestos en los capítulos sobre la valentía, la cobardía, la generosidad o la mesura. Por esta razón podemos encontrar noticias relevantes para el estudio de este asunto en el capítulo segundo ${ }^{33}$ Bāb hamdu -l-lisān wa-faḍl al-bayān ["Capítulo sobre la expresión y elogio de la elocuencia"] y en el cincuenta y ocho ${ }^{34}$, Bāb al-harb wa-l-šâya $\bar{a}^{\prime} a$ wa-lŷaban ["Capítulo sobre la guerra, la valentía y la cobardía"].

El sayyid árabe no era sólo una figura importante por su condición de capitán de las tropas en el combate pues sus obligaciones y responsabilidades iban mucho más allá. Debía aportar sus bienes para ayudar a las familias de los prisioneros de su grupo a rescatarlos, tenía que preocuparse por la suerte de viudas y huérfanos de la tribu, debía administrar justicia entre los suyos, además de ofrecer hospitalidad a los viajeros que pasaran por el campamento, a los que según la ley consuetudinaria de Arabia debían alimentar o proteger. A cambio recibían una cuarta parte del botín alcanzado en las razias o incursiones contra las tribus enemigas, porcentaje que el Corán redujo a un quinto, atribuido posteriormente al estado islámico. Por esta razón, algunas de las virtudes apreciadas para que una persona fuera sayyid tenían relación con la guerra y otras estaban ligadas a la protección de los más débiles. Se trataba de un primus inter pares, de una persona que recibía un reconocimiento a su valía y sus hechos en favor de su grupo, que no podía legar a sus descendientes y que debían mantener en todo momento una postura respetuosa hacia sus compa-

32. Ibn 'ABD AL-BARR, Bahŷat al-mẫālis, ed. Muhammad Mūsà al-Jawālī y 'Abd al-Qādir al-Quțț, I, pp. 598-614.

33. Idem, I, pp. 54-59.

34. Idem, I, pp. 467-483. 
ñeros. En comparación con los héroes de la épica francesa o de otras tradiciones europeas, que se encontraban en una situación un tanto irreal, apartados de la vida cotidiana, los de la épica árabe se encontraban enraizados en su medio, y el resultado de una acción guerrera notable podía ser un botín de cuatro o cinco camellos con los que alimentar a los miembros de una tribu ${ }^{35}$.

Vamos a destacar algunas menciones acerca de la forma en que entendían los árabes y transmitían los andalusíes del siglo XI las virtudes de estos personajes, centrándonos en la característica más destacada por las distintas fuentes y que parece retratarles como ninguna otra: el hilm, palabra que podemos traducir como magnanimidad y mesura. En primer lugar es necesario destacar que no había ninguna señal externa que permitiera identificarlo ${ }^{36}$, razón por la que su posición se mostraba por toda una serie de pequeños detalles a los que debemos prestar atención. De hecho, para saber quién era el dirigente de una tribu, los visitantes debían preguntar por él en caso de no conocerlo, aunque las virtudes que todo arraez debía tener permitían, al menos, dar una orientación ${ }^{37}$ :

“Dijo: Preguntó 'Umar b. 'Abd al-'Azīz a un hombre ¿Quién es el sayyid de tu tribu? Respondió: ¡Yo!, y repuso: Si lo fueras, no lo dirías”.

El hecho de presumir de tener tal precedencia dentro de su tribu iba en contra de la modestia que debía gobernar la actuación de un sayyid.

Uno de los personajes más destacados de la época omeya, del que sabemos además que era un ejemplo admirado por el propio Rodrigo Díaz, que conoció y admiró sus hazañas en Valencia según nos cuenta el antólogo andalusí Ibn Bassām $^{38}$, definía así la forma de reconocer la condición de sayyid de una persona:

"Preguntaron a Muhallab: ¿Qué hace sayyid a un hombre? Respondió: que monte en su casa solo y vuelva a ella con una multitud" ${ }^{39}$.

Resulta curioso que un personaje que había de guiar a la guerra a su tribu fuera sistemáticamente descrito como refractario a cualquier conflicto con los, en ocasiones, pendencieros compañeros de tribu, tanto de acto como de palabra:

“Dijo al-Marrār b. Sa'īd:

- Si quieres ser un día sayyid de tu tribu no propagues tonterías ni insultos" ${ }^{\prime 40}$.

35. J. RAMíREZ dEL Río, op. cit., pp. 107-111.

36. En algunas fuentes se dice, por el contrario, que al sayyid le correspondía un turbante color azafrán, aunque esto parece desmentido por las referencias concretas a las dificultades para distinguirlos durante el combate.

37. Ibn 'AbD AL-BARR, op. cit., I, p. 608; J. RAmírez del Río, La Orientalización de al-Andalus. Los días de los árabes en la península Ibérica, p. 111.

38. Ibn BASSĀM, Al-Dַaj̄̄ra fì mahāsin ahl al-ŷazīra, ed. I. 'Abbās, Beirut, 1977, p. 100; M.A. MAKKI, op. cit., pp. 205-213.

39. Ibn 'ABD AL-BARR, op. cit., I, p. 608.

40. Idem, I, p. 609. 
Los mismos hombres que ostentaban esta función sabían cuán escasa era su autoridad y las dificultades que sufrirían en caso de intentar hacerla más sólida. Su principal valedor era su mismo ejemplo ${ }^{41}$ :

“Dijo Ahnaf b. Qays un día a su gente: Soy de vuestros hombres el que no tiene superior. Sin embargo os doy preferencia, os regalo con mis bienes, defiendo vuestros derechos y guardo vuestro honor. El que hace lo que yo, es como yo. El que hace más que yo, es mejor que yo, y soy mejor que el que hace menos que yo. Le dijeron: ¡A bū Muhammad! ¿Qué te lleva a decir eso?, y respondió: ¡Así os invito a que tengáis nobles costumbres!".

El propio sayyid era consciente en todo momento de la necesidad de mantener un comportamiento que sus compañeros de tribu definieran como modélico y que no pudiera suponerse que favorecía a sus familiares frente a los demás miembros del grupo. Ibn 'Abd al-Barr nos muestra un ejemplo notable, el de Sālim b. Nawfil ${ }^{42}$ :

“Era Sālim b. Nawfil sayyid de los Banū Kināna en su tiempo. Un hombre saltó sobre su hijo y sobre su sobrino y los hirió. Llegó a él Sālim y le dijo: ¿Qué te pone a salvo de mi venganza? Dijo: No te habrían hecho jefe si no contuvieras tu ira y no fueras benévolo con el ignorante ni soportaras al desgraciado".

De Sālim dijo el poeta:

(Metro țawīl, rima lam).

- “Hacemos sayyid a mucha gente, mas no merece la señoría sino el famoso Sālim b. Nūfil!".

Ibn 'Abd al-Barr comienza el capítulo acerca de los sayyid-es árabes con una cita de Abū 'Amr b. al-'Alà acerca de las condiciones necesarias para alcanzar la condición de sayyid, resumida en seis virtudes fundamentales ${ }^{43}$ :

“La gente de la Ŷāhiliyya no tomaba por sayyid más que al que tenía seis virtudes, que el Islam completó con una séptima: generosidad [al-sajā'], valentía [al-naŷda], resistencia [șabr], magnanimidad [hilm], elocuencia [al-bayān] y juicio [al-hasab], y en el Islam se añadió la continencia [al-'afāf]".

Debemos tener en cuenta que estas virtudes tenían un significado y un contexto muy concreto, que les confería un sentido algo diferente al nuestro, como podremos comprobar más adelante.

Las condiciones citadas debían ser cumplidas en mayor o menor grado aunque el propio autor destaca el hecho de que algunos personajes alcanzaron la jefatura de su tribu a pesar de faltarles alguna de las virtudes señaladas ${ }^{44}$ :

41. Idem, I, pp. 600-601; J. RAMírez del Río, La Orientalización de al-Andalus..., p. 111.

42. Idem, I, p. 603; J. RAmírez del Río, La Orientalización de al-Andalus..., p. 112.

43. Idem, I, pp. 601-602; J. RAmíreZ del Río, La Orientalización de al-Andalus..., p. 111.

44. Idem, II, p. 610; J. RAmíreZ del Río, La Orientalización de al-Andalus..., p. 110. 
"Las acciones alabadas y las buenas costumbres (ajlāq ŷamīla) obligan a otorgar la jefatura, y las acciones criticadas y las costumbres viciosas la imposibilitan; sin embargo vemos que algunas tribus escogieron como jefes a hombres cuyas costumbres no se podían alabar, y con hechos que no satisfacían. Entre ellos: aunque la estupidez impedía la jefatura, fue elegido sayyid 'Uyyina b. Hiṣn, que era estúpido; fue sayyid Abū Sufyān, que era un avaro, aunque la avaricia impedía ser jefe. Fue elegido 'Āmir b. al-Ṭufayl, que era un libertino, aunque el libertinaje impedía ser jefe. Fue elegido sayyid Abū Ŷahl, que no dejó (por ello) de beber, y entró en la asamblea y no sufrió daño su barba. La juventud impedía ser jefe, y fue elegido Šibl b. Ma'bad al-Baŷālī porque no había en Basora hombre más honrado que él".

El sayyid podía ser un hombre joven aunque sólo en condiciones excepcionales; sin embargo este término no tenía el sentido que le damos hoy día. En la Arabia preislámica una mujer que según nuestras concepciones sería muy joven se podía ver ya en una situación impensable ${ }^{45}$ :

"Lo siguiente me lo dijo Ishāā b. Raḥwayh: Me dijo Yahyyà b. Ādam que alHasan dijo: Conocí a una abuela que no tenía más de veintiún años".

Sin embargo desearía llamar la atención acerca del hecho de que una de las cosas que no podía sufrir un sayyid árabe era que le ofendieran tirando y estropeando su barba. Siempre hemos dado por descontado que "...aquesta barba que nadi non messó" 46 era una reminiscencia de una costumbre germánica, que hacía de la tonsura o de la pérdida del cabello una grave falta al honor personal. Pero esto se aplicaba no a la barba sino al pelo de la cabeza, cuya tonsura impedía seguir manteniendo las funciones de rey entre los visigodos, por ejemplo. Entre los árabes el tener una barba no afrentada, no mesada, era una condición sine qua non del sayyid.

En las breves menciones anteriores hemos podido observar cómo las virtudes más apreciadas permitían alcanzar la condición de sayyid. Aunque tenemos que destacar que la virtud más destacada con mucha diferencia en estos dirigentes era el hilm . $^{47}$.

Vamos a mostrar algunos ejemplos de la forma en que los árabes definían las virtudes enumeradas en el texto anterior por Ibn 'Abd al-Barr, pues en algunos casos no se corresponde totalmente con la traducción que ofrecemos y no podían ser aprehendidas de manera intuitiva:

45. Ibn QuTAYBA, The Natural History Section from the $9^{\text {th }}$ century 'Uyūn al-Akhbār, trad. L. Kopf, París, 1949, p. 28.

46. Poema de Mio Cid, ed. A. Montaner, Barcelona, 2000, p. 179, verso 2836. Hay menciones a la barba como elemento representativo del honor del Cid en p. 86, versos 1238-1239: "Ya l'crece la barba e vale allongando / dixo mio Cid de la su boca atanto / por amor del rey Alfonso que de tierra me á echado / nin entrarié en ella tigera ni un pelo non avrié tajado / e que fablassen d' esto moros e cristianos", y caracteriza al héroe como podemos advertir en p. 84, verso 1226: "arrancólos mio Cid el de la luenga barba", entre otras muchas menciones: p. 64, verso 926, p. 69, verso 1011, p. 96, verso 1238, p. 156, verso 2410.

47. Cfr. B. FARes, L'Honneur chez les arabes avant l'Islam, París, 1932. 
"Preguntaron a 'Abd Allāh b. 'Umar por los requisitos del sayyid, y él respondió: La generosidad y la mesura... dijo 'Abd Allāh b. ‘Umar: Nosotros, en la tribu de Qurayš, consideramos que la generosidad y la mesura dan la jefatura y consideramos que la continencia y la buena dirección con los [propios] bienes son la base de la hombría" ${ }^{48}$.

En las páginas siguientes abordaremos las diferentes virtudes señaladas de modo independiente por comodidad expositiva; sin embargo es necesario señalar que todas ellas formaban una unidad indivisible: sin șabr resultaría imposible que el sayyid pudiera ejercer el hilm, sin naŷda o saŷa'a no tendría los bienes necesarios para dispensar al-saja $\bar{a}^{\prime}$ a sus compañeros de tribu... Todas las características señaladas habían de confluir en un mismo personaje en diferentes proporciones para llevar a cabo su tarea.

\section{GENEROSIDAD $\left[A L-S A J \bar{A}^{\prime}\right]$}

El sayyid de una tribu debía atender a toda una serie de necesidades de la misma que le forzaba a gastar sus propios bienes. No había institución alguna que reuniera recursos del colectivo para prestar atención a las necesidades de los miembros más débiles, pero el propio sayyid debía usar sus propiedades para atender a los huérfanos, a las viudas y para rescatar a los prisioneros. Por esta razón cuando las fuentes se refieren a la generosidad de estos personajes no podemos entenderla en el sentido que le damos nosotros sino más bien en el acertado cumplimiento de estos deberes; no se trataba por tanto del ofrecimiento libre de los propios bienes sino de su uso siguiendo unos parámetros sociales muy concretos, reconocidos por la moral tribal ${ }^{49}$.

Las condiciones de vida de los árabes en medio desértico eran duras y los períodos de hambre, frecuentes. Por ello algunas de las menciones más importantes a esta virtud se refieren al uso de los bienes del sayyid para calmar el hambre de sus compañeros. Una mención que aclara la importancia de esa virtud entre los sāāât árabes se remonta al antepasado lejano de los 'abbāsíes:

“Dijo Mașqala b. Hubayra al-Šaybānī: Escuché a Șa'șa'a b. Șuhān que preguntó a Ibn 'Abbās: ¿Qué hace que distingáis como sayyid a alguien? Respondió: El invitar a comer, ser agradable al hablar, ofrecer regalos, abstenerse de preguntar, tratar con amabilidad tanto al grande como al pequeño y que la gente vea que respeta sus derechos" ${ }^{\prime 50}$.

“Preguntaron a 'Abd Allāh b. 'Umar por los requisitos del sayyid, y él respondió: La generosidad y la mesura [al-hilm]”"51.

\footnotetext{
48. Ibn 'ABD AL-BARR, op. cit., I, pp. 600-601.

49. J. RAMírez del Río, La Orientalización de al-Andalus..., pp. 109-170.

50. Ibn ‘ABD AL-BARR, op. cit., I, p. 600.

51. Idem.
} 
El sayyid más famoso de Arabia por su generosidad era Hātim, que sigue siendo hoy día el paradigma de la generosidad en el mundo árabe. El siguiente poema muestra con claridad cuál era su forma de actuar ${ }^{52}$ :

(Metro țawīl, rima dal).

- “¡Hija de 'Abd Allāh, hija de Mālik!

¡Hija del de los dos vestidos, y del caballo bravo!

- ¡Si sabéis de algo mejor que lo que os he ofrecido, tomadlo pues no guardo esa comida para mí!

- ¡Sea cerca o lejos temo que me critiquen cuando muera!".

La capacidad de un guerrero para dar de comer a los miembros de su grupo en las épocas difíciles gracias al uso de sus bienes y a la posibilidad de arrancar recursos de los que alimentar a los demás era un rasgo necesario en los sayyid árabes que encuentra su adecuado reflejo en la caracterización del Cid cuando indica a sus familiares en el verso 1644: "afarto veran por los ojos / cómmo se gana el pan".

Lejos de tratarse de una sola mención en el texto, la obsesión del personaje central del CMC es el poder dispensar bienes de manera continuada sobre todos los miembros de su grupo como podemos observar en el verso 688: "si venciéramos la batalla, creçremos en rictad", 806-810: " ¡Dios, qué bien pagó a todos sus vassallos/ a los peones e a los encabalgados!/ Bien lo aguisa el que en buena hora nasco / cuantos él trae todos son pagados".

\section{VALENTÍA [NA $\left.\hat{Y} D A, S A \hat{Y} A^{\prime} A\right]$}

El jefe de una tribu debía dirigirla en el combate y por esta razón debía ser avezado en la guerra y sus trampas y valiente. El hecho de no cumplir con esta condición podía inhabilitar a una persona para ser sayyid ${ }^{53}$ :

“Dijeron algunos árabes: ¿Cuál es la característica de vuestro sayyid? Dijeron: Es al que tememos cuando avanza y al que criticamos, y del que murmuramos, cuando retrocede".

El sayyid debía conseguir, con su capacidad guerrera, recursos para asegurar la supervivencia de la tribu, por lo que su inacción era tenida como muestra de falta de arrojo y de inteligencia ${ }^{54}$.

52. Idem, I, p. 293; capítulo sobre el huésped. El último verso también aparece en la página 792 de la misma obra, en el capítulo sobre la memoria y la loa; J. RAMíreZ DEL Río, La Orientalización de al-Andalus..., p. 122.

53. Idem, I, p. 608.

54. Ibn 'ABD AL-BARR, op. cit., p. 234. Verso que nos recuerda éste del Poema de Mio Cid (p. 65, versos 947-948): "Ya cavalleros! Dezirvos he la verdad / qui en un lugar mora siempre lo so puede menguar". 


\section{(Metro țawĩl, rima $b a$ ).}

- “iCuando la gente permanece en sus tiendas, les ves ajenos a la posibilidad de conseguir ganancias!".

La valentía de un sayyid no debía sin embargo alcanzar la temeridad, y debía en todo momento cuidar por la integridad de los miembros de su grupo antes que por conseguir grandes riquezas.

Este rasgo de la descripción de los héroes puede en principio parecer poco propicio para establecer diferencias entre las diferentes tradiciones literarias, pues en todas ellas la valentía es un rasgo imprescindible. Sin embargo, el carácter verista de las narraciones de los ayyām al-'arab, en que las batallas enfrentan a grupos de unas decenas de caballeros, facilita que la forma de expresar esa valentía sea mucho más similar a la del Poema de Mio Cid que a la épica francesa. En el poema se destaca la condición heroica del Cid porque atiende a las necesidades de los suyos, con los que comparte incluso el parco botín del robo a Rachel y Vidas.

\section{RESISTENCIA (STABR)}

La resistencia o la paciencia, que de ambas formas puede ser entendida la palabra árabe șabr, se refiere a la capacidad para afrontar con entereza los reveses de la fortuna, sin dejarse doblegar por las derrotas ni ensoberbecer por las victorias. Esta ecuanimidad era tenida en mucho a la hora de elegir un sayyid, pues con la multitud de combates a la que se veían abocados los árabes de la Arabia preislámica y de los primeros tiempos del islam era difícil que no sufrieran derrotas o pérdidas de seres queridos. El ser capaces de afrontarlos sin mostrar desesperación era una cualidad muy alabada; la grandeza de ánimo para sobreponerse a las dificultades era una cualidad que distinguía a héroes como Qays b. Zuhayr o 'Amr b. Ma'dīkarīb.

Ibn 'Abd al-Barr nos llega a decir que el siguiente verso del sayyid Durayd b. al-Șimma era considerado por algunos críticos como el más hermoso de los escritos por los árabes. Es el que dedicó a su hermano 'Abd Allāh, muerto en batalla:

(Metro țawīl, rima dal).

- "Se quejaba poco de las desgracias y pensaba en el día los problemas que habrían de llegar al siguiente" ${ }^{\prime 25}$.

El ser resistente en los combates y saber esperar la oportunidad, sin dejarse llevar por el miedo o por el ardor, era muy necesario para el combate en el medio desértico y la paciencia resultaba imprescindible para actuar de forma

55. Ibn ‘ABD AL-BARR, op. cit., p. 362. 
medida dentro del campamento. Esta paciencia y resistencia, sin embargo, no eran en modo alguno pasiva o fatalista, sino una forma de superar adversidades para poder vencer al enemigo o sobrevivir a una adversidad de forma activa. En ocasiones estas duras condiciones llevan a los sayyid-es al cinismo. Un comportamiento similar es el del Cid cuando al comienzo del Poema -verso 14- le dice el Cid a Alvar Fáñez:

“ ¡Albriçia, Albar Ffañez ca echados somos de tierra!”.

O la reacción tras conocer la ofensa sufrida por sus hijas en Corpes, detallada en los versos 2828-2829:

\section{"Quando gelo dizen a mio Çid el Campeador / una grand ora pensso e comidio".}

Ambas acciones serían imposibles en un héroe de la épica francesa, en la que el ímpetu es destacado por encima de cualquier otra cualidad en los personajes heroicos, que deben devolver centuplicada cualquier ofensa. El Cid, en estos casos, se muestra muy al contrario como șabūr [resistente, paciente].

\section{Mesura (HILM)}

La figura más destacada por las fuentes a la hora de referirse al hilm es la del primer califa omeya, Mu'āwiya. La principal virtud de un sayyid en su comportamiento con los demás miembros de su comunidad era, precisamente, su capacidad para no actuar de forma orgullosa, para no molestar a los demás con su precedencia y poderío, con lo que el hilm lo podríamos definir en un primer momento como modestia. En este sentido la mención de la Bahŷat almầālis resulta muy clara:

“Cuando mencionan las razones del mando de Mu'āwiya b. Abī Sufyān dicen: Se desplazaba por el campamento como si fuera la oscuridad misma"56.

A pesar de tratarse del monarca más poderoso de su tiempo, el ceremonial que rodeaba a este personaje, tal y como se describe en las fuentes árabes, resultaba extremadamente sencillo. Hay otras muchas anécdotas en la obra en que esa modestia se ve ejemplificada por el hecho de que $\mathrm{Mu}^{\prime}$ āwiya no castigara a algún insolente de alguna tribu aliada y se limitara a irse de su compañía tras un insulto ${ }^{57}$, hecho que no dejaba de alabarse tanto por la condición de califa como por evitar así disputas con las demás tribus.

Esta cualidad era ponderada por encima de las demás, y el famoso antólogo y estudioso de la Arabia preislámica al-Așma' $\mathbf{1}$, citado por Ibn 'Abd al-Barr, indica:

56. Idem, I, p. 607.

57. R. Dozy, Historia de los musulmanes de España, Madrid, 1984, I, p. 53. 
"Se decía: no se reúnen diez sin que haya entre ellos un guerrero o más, pero puedes juntar a mil sin que entre ellos haya un hombre magnánimo [halīm $]^{58}$.

La función de hākim o juez que cada sayyid había de desempeñar en el interior de su tribu explica en buena medida esa mesura. Un castigo excesivo a un miembro de la comunidad podía suponer la quiebra de la solidaridad tribal.

“Dijo Mu'āwiya: Intento considerar las cosas de manera que mi magnanimidad sea mayor que la culpa" 59 .

La forma en que la Bahŷat al-mâyālis pondera la figura de este califa por esta virtud nos muestra cómo era considerada la quinta esencia del sayyid árabe.

“Preguntó Mu'āwiya a 'Amr b. al-'Aṣ: ¿Quién es el hombre más elocuente? Respondió: quien deja a un lado la curiosidad y se reduce a lo esencial. ¿Y quién es el más paciente? Respondió. Quien cambia su mundo por las bondades de su religión. Preguntó: ¿Quién es más valiente?. Dijo: Quien cambia su ignorancia en mesura" $^{\prime 60}$.

En el Poema de Mio Cid hay distintos momentos en que la mesura del protagonista asemeja el comportamiento de los héroes árabes. Así, tras la batalla de Castejón, en los versos 486 a 493 el Cid le dice a Minaya Albar Fáñez que tome el quinto del botín, indicando así que el sayyid o jefe de esta batalla ha sido él, pues le entrega la precedencia debida al guerrero al mando en una batalla victoriosa $^{61}$, de modo similar a lo que hizo en los días de al-Taytal y al-Nibāŷy el sayyid Qays b. 'A Așim ${ }^{62}$. El mismo hecho de tomar el quinto del botín ya nos indica un claro influjo árabe como señaló en su día Américo Castro ${ }^{63}$.

Este comportamiento es mucho más propio de las tradiciones de los ayyām al-'arab que de las jactanciosas disputas entabladas entre los caballeros de la épica franca tras una victoria. El comportamiento del Cid en este asunto recuerda a la frase que indicamos anteriormente, en que 'Umar b. 'Abd al-'Azīz hace ver a un árabe que no puede ser el sayyid de su tribu porque dice que lo es. Alvar Fáñez decide llevar esta parte del botín al rey Alfonso para solicitar el perdón; no debemos olvidar que este comportamiento colectivo se encuentra bastante en consonancia con las tradiciones descritas por Ibn 'Abd al-Barr en la Bahŷat al-mâ̂ālis.

\footnotetext{
58. Ibn 'ABD AL-BARR, op. cit., I, p. 602.

59. Idem, I, p. 615.

60. Idem.

61. Poema de Mio Cid, vv. 486-493.

62. Ibn 'AвD RABBiHĪ, El libro de las batallas de los árabes, edición, introducción, estudio y notas, J. Ramírez del Río, Madrid, 2002, pp. 38-40 del texto árabe y 51-52 de la traducción.

63. A. CAStro, España en su historia, Madrid, 1983 [reed. de la de 1946], pp. 71-77.
} 


\section{ELOCUENCIA [AL-BAYĀN]}

Hay un capítulo entero dedicado en la Bahŷat al-maŷālis a la elocuencia y la claridad de expresión [capítulo 5]. El elogio de la elocuencia es frecuente en las obras de adab y en la Bahŷat al-maŷälis es muy frecuente. Sin embargo, la discreción era una cualidad muy apreciada en los sādāt. Resulta frecuente encontrar menciones al silencio cuando se trata de la elocuencia, cosa sorprendente a primera vista. La forma de conciliar ambos aparece en la Bahŷat de forma sorprendente:

\footnotetext{
“Dijeron: el silencio es paz y la palabra acertada, ganancia; el botín es mejor que la paz"${ }^{\prime \prime 4}$.
}

La influencia de las palabras en el comienzo de los conflictos quedó reflejada en un verso de Hudayfa b. Yaman recopiladas por Ibn 'Abd al-Barr"

"El comienzo de las guerras se encuentra en las palabras".

El sayyid debía ser capaz de insultar al enemigo y de defender a los suyos no sólo con las armas en la lucha sino también en las disputas y mediante los poemas que se difundían de un lugar a otro. El verso que mejor refleja este hecho es el del gran poeta Imrū-l-Qays ${ }^{66}$ :

"La herida causada por la lengua es como la provocada por la mano".

La buena expresión debía servir para la defensa de los derechos propios frente a otros grupos tribales tanto en el combate como en períodos de paz. Este aspecto relativo a la forma de dirigirse a los demás de los héroes árabes en el combate fue analizado por A. Galmés de Fuentes ${ }^{67}$.

Resulta evidente la capacidad mostrada por el Cid en las diferentes ocasiones en que se expresa en público a lo largo del texto del Cantar, en especial en el caso de las cortes de Toledo. La forma mesurada de expresarse en estas cortes, indudablemente ceñidas al derecho castellano como mostró E. Lacarra ${ }^{68}$, no se corresponde a otros casos de la épica franca pero sí se corresponde con la forma en que los sayyid-es se expresaban en presencia de los califas ortodoxos y los omeyas.

\section{JUICIO $[A L-H A S A B]$}

Algunas de las virtudes anteriores pueden llevarnos a la conclusión de que la inteligencia en la dirección de una tribu forma parte del hilm. Sin embargo, en la descripción de Ibn 'Abd al-Barr encontramos referencias a la sagacidad y la

\footnotetext{
64. Ibn 'ABD AL-BARR, op. cit., I, p. 55.

65. Idem, p. 468.

66. Idem, p. 59.

67. Épica árabe y épica castellana, Barcelona, 1978.

68. E. LACARra, El Poema de Mio Cid: realidad histórica e ideológica, Madrid, 1980.
} 
astucia del sayyid para dirigir acertadamente a la tribu en los conflictos y en las distintas circunstancias que pudieran encontrarse. Este aspecto fue transmitido a los héroes árabes de al-Andalus que debían mostrar su habilidad en las narraciones bélicas como destacó D. Oliver ${ }^{69}$. En ocasiones encontramos distintas versiones referentes a una misma batalla en las que se intenta demostrar que la victoria ha sido obtenida mediante el engaño y como destacó M.A. Makkī la principal razón para la admiración de Rodrigo Díaz por Muhallab era su capacidad para imponerse a enemigos superiores gracias a su astucia.

Este tipo de astucia lo podemos encontrar tanto en el campo de batalla como fuera de él. Curiosamente contamos con un referente adecuado para el Cid en el propio al-Andalus, donde un caballero, al-Surunbaqī, precedió al Cid engañando a unos judíos para que pagaran su rescate a los vikingos que lo habían capturado ${ }^{70}$ :

"Sa' dūn b. Fath al-Surunbāqī... lo apresaron los maŷūs que llegaron a la costa occidental de al-Andalus en tiempos del emir Muhammad, y lo rescató un mercader judío que buscaba conseguir ganancias; (Sa'dūn) prometió al judío recompensarle hasta que consiguió huir de él, pero luego defraudó su confianza y le hizo perder su dinero".

Algunos críticos mencionaban la sorpresa que les producía la treta del Cid sufrida por Rachel y Vidas ${ }^{71}$, señalando que era un tanto impropia de un héroe épico. Sin embargo como podemos apreciar resultaba normal en el contexto de la tradición épica andalusí. Debemos aclarar desde el primer momento que no es nuestro propósito sostener que el episodio del fraude a los judíos del Poema de Mio Cid proceda de esta narración. No obstante, resulta evidente que la manera en que el Cantar describe al Cid se encuentra en consonancia con la manera de describir a los personajes heroicos de al-Andalus en multitud de aspectos.

El mozarabismo de uno de los dos autores de esta obra, postulado por Menéndez Pidal, ha dado lugar a que distintos aspectos de la obra hayan sido estudiados desde el prisma de los posibles influjos árabes, pero la descripción que mostramos en estas páginas, y que indudablemente requerirá futuros trabajos, parece apuntar a una dependencia más directa de algunos modelos andalusíes de lo que hasta ahora sospechábamos.

69. D. Oliver Pérez, «Las batallas del Cantar de Mio Cid desde la perspectiva de la historiografía árabe», Revista de Historia Militar, XXXVI, 1992, pp. 15-52 y de la misma autora: «Una nueva interpretación de la batalla de Alcocer», Revista de Historia Militar, XXXVII, 1993, pp. 15-44.

70. Ibn HAYYĀN, Al-Muqtabis, III, ed. Antuña, París, 1937, p. 23. Ya llamamos la atención sobre este hecho en el artículo «Notas acerca de un texto épico en al-Andalus», Anaquel de Estudios Árabes, XIV, 2001, pp. 219-230.

71. N. Salvador Miguel, «Reflexiones sobre el episodio de Rachel e Vidas en el Cantar de Mio Cid», RFE, 59, 1977, pp. 183-225 y del mismo autor: «Unas glosas más al episodio de Rachel y Vidas en el Cantar de Mio Cid», Serta Philologica F. Lázaro Carreter, Madrid, 1983, II, pp. 493498; C. Alvar, «El Poema de Mio Cid y la tradición épica: breves comentarios», El Cid, de la materia épica a las crónicas caballerescas, Madrid, 2002, pp. 9-21, especialmente pp. 13-14. 


\section{LOS SAYYID-ES EN AL-ANDALUS EN EL SIGLO XIII}

En general solemos asumir que la institución del sayyid árabe limitó su vigencia en al-Andalus a los tiempos en que la institución tribal mantuvo su pujanza. Sin embargo, como destacamos en La Orientalización de al-Andalus, el proceso de arabización cultural significó la prescripción de una serie de modelos y de paradigmas sociales que se impusieron en al-Andalus debido al prestigio social que los acompañaba, independientemente de la etnia a la que perteneciera cada persona o grupo social. Por esta razón y aunque los modos de vida propios de la vida tribal habían desaparecido en épocas relativamente tempranas, se mantuvo la categoría de sayyid de distintos grupos tribales hasta fechas tardías, en formas similares a lo que podemos encontrar en el caso de Ibn 'Abd al-Barr. Así, pocos años antes de la caída de Sevilla en manos de los cristianos, encontramos la biografía de un sabio de Tejada [Țalyāța] que era el sayyid de su tribu.

Las referencias que contamos con menciones similares a un sayyid en este período suelen aludir a los descendientes del califa almohade 'Abd al-Mu'min, pero esta sola mención puede mostrar que la palabra sayyid era todavía utilizada en el siglo XIII para designar a un jefe tribal en un mundo que había cambiado por completo.

\section{A MODO DE CONCLUSIÓN}

La palabra sayyid ha tenido una historia muy larga en la cultura árabe y ha designado distintas realidades a lo largo del tiempo. Este hecho no debe llevarnos a concluir que se trataba de una denominación vagamente respetuosa aplicada a un guerrero castellano victorioso en el al-Andalus del siglo XI y adoptada posteriormente en un texto épico. La condición de sayyid era perfectamente conocida en esta época y las virtudes que debían adornarlo se encontraban codificadas en una tradición que contaba en aquel momento con varios cientos de años y que había sido compilada por un sabio que residió y murió en el Levante pocos años antes de que Rodrigo Díaz comenzara sus campañas por esta región. Resulta clara la dependencia de la caracterización del Cid en el Poema de modelos formales procedentes de la tradición árabe, que dan lugar a un personaje heroico muy diferente de los procedentes de modelos franceses.

El hecho de que este personaje recibiera el apelativo de sayyid no debe entenderse como el mero uso de una palabra de origen árabe sin mayores consecuencias, sino la aplicación de un apelativo que respondía a las características que este personaje de frontera recibió por parte de un grupo humano que se encontraba en la transición entre el mundo andalusí y el castellano. Por otro lado no debemos irnos al otro extremo y defender un origen únicamente andalusí del CMC; resulta evidente que se trata de un personaje perteneciente al mundo cristiano, por más que su condición fronteriza lo aproxime a modelos árabes, y apartarlo de esa realidad supone desvirtuarlo de forma grave. 


\section{RESUMEN}

El sobrenombre árabe por el que es conocido Rodrigo Díaz de Vivar, el Cid, procedente del sayyid árabe, lejos de ser un título simplemente respetuoso hacia el caudillo militar lleva consigo toda una serie de rasgos que identifican al sayyid de las tribus beduinas. Estas figuras y los rasgos de su carácter pasarían al acervo propio de los árabes, que los extenderían en el tiempo allá donde fueran. Se analizan en el presente trabajo esos rasgos del sayyid según una obra de adab cercana a la aparición del Cid en Valencia, la Bahŷat al-maŷālis de Ibn 'Abd al-Barr (368/978-463/1071), poniéndolos en relación con los rasgos de Rodrigo Díaz de Vivar según el Cantar de Mio Cid.

Palabras clave: Rodrigo Díaz de Vivar, Cid, sayyid, héroe, beduino, Ibn ‘Abd al-Barr, Bahŷat al-mâyālis.

\section{ABSTRACT}

The Arabic nick name by which is known Rodrigo Díaz de Vivar, the Cid, from the Arabic sayyid, far from being a title just respectful towards the war lord carries a number of features that identify the sayyid of the Bedouin tribes. These figures and their character traits would be a part of the cultural heritage of the Arabs, who would spread it over time and wherever they went. We analyze here these features of the Sayyid as appear in a work of adab composed close to the presence of the Cid in Valencia, the Bahyat al-maŷalis of Ibn 'Abd al-Barr (368/978-463/1071), relating them to the features of Rodrigo Díaz de Vivar as appear in the Cantar de Mio Cid.

Key words: Rodrigo Díaz de Vivar, Cid, Sayyid, Hero, Bedouin, Ibn ‘Abd al-Barr, Bahŷat al-maŷālis. 